\title{
Future changes in the relationship of precipitation intensity in Eastern Mediterranean with large scale circulation
}

\author{
M. Hatzaki ${ }^{1}$, H. A. Flocas ${ }^{1}$, C. Oikonomou ${ }^{1}$, and C. Giannakopoulos ${ }^{2}$ \\ ${ }^{1}$ Department of Environmental Physics and Meteorology, Faculty of Physics, University of Athens, Athens, Greece \\ ${ }^{2}$ Institute for Environmental Research and Sustainable Development, National Observatory of Athens, Athens, Greece
}

Received: 26 February 2009 - Revised: 9 September 2009 - Accepted: 23 November 2009 - Published: 10 March 2010

\begin{abstract}
The objective of this study is to investigate the linkage of large-scale upper air circulation over the greater European area with intense precipitation events over Eastern Mediterranean and then to estimate potential changes in the atmospheric patterns in the future, under global warming conditions. For this purpose, results from the regional climate model HadRM3P and Global Circulation Model HadAM3P have been used for the present period 19601990 (control run) and the future period 2070-2100 based on the B2a IPCC emission scenario. For the identification of the precipitation extremes the Simple Daily Intensity Index (SDII) was employed. Our analysis has shown a notable relation of extreme events with the East Atlantic and Scandinavia teleconnection patterns, as well as the Eastern Mediterranean Pattern (EMP) during the wet period. In the future, similar patterns are found, with different magnitude and position, following the projected changes in atmospheric circulation over Europe.
\end{abstract}

\section{Introduction}

Understanding the physical processes that influence the occurrence of extreme precipitation events is of great importance to explain their changes in the present climate and, consequently, any projected future changes. The relationship between these events in the Mediterranean and largescale atmospheric circulation patterns at surface or upper troposphere can help to disclose the underlying physical processes and has been extensively studied with the aid of synoptic classification or multivariate methods (e.g. Maheras et al., 1999; Kutiel et al., 2002; Haylock and Goodness, 2004; Littman et al., 2000; Houssos et al., 2008; Tartaglione et al.,

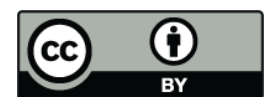

Correspondence to: M. Hatzaki (marhat@phys.uoa.gr)
2009; Hatzaki et al., 2009). These studies revealed the important role of low frequency climatic variability in changes of the extreme precipitation regime in Mediterranean, including North Atlantic Oscillation, Mediterranean Oscillation, North-Caspian Sea pattern, and Eastern Mediterranean Pattern (Hatzaki et al., 2009).

The assessment of changes in precipitation extremes in a human-induced future climate is an important issue, considering their huge socio-economic impacts and can be used as a guideline for the development of appropriate adaptation and mitigation strategies (e.g. Fowler and Kilsby, 2003). Less attention has been given to the assessment of the extent in which large scale changes can explain projected changes in the occurrence of heavy precipitation in the Mediterranean (Santos et al., 2007). The objective of this study is to explore any potential future changes in the large scale circulation patterns associated with intense precipitation events in the Eastern Mediterranean (hereafter it will be referred as EM).

\section{Data and methodology}

In this study the following datasets are employed: (a) daily precipitation amounts in EM, as derived from the regional climate model of the UK Hadley Centre HadRM3P, have been used for the present period 1960-1990 (control run) and the future period $2070-2100$, available on $0.44^{\circ} \times 0.44^{\circ}$ latitude by longitude grid, available through the European project MICE (Modelling Impacts of Climate Extremes) and (b) daily values of geopotential height at the isobaric level of $500 \mathrm{hPa}$ on $2.5^{\circ} \times 2.5^{\circ}$ latitude by longitude grid, as derived from the Global Circulation Model HadAM3P for the same present and future period, available through the European project STARDEX (Statistical and Regional dynamical Downscaling of Extremes for European regions). Future data are based on the B2a IPCC emission scenario. The B2 storyline and scenario family describes a world in which the

Published by Copernicus Publications on behalf of the European Geosciences Union. 
emphasis is on local solutions to economic, social, and environmental sustainability. Moreover, this scenario is oriented toward environmental protection and social equity, while its accompanying emissions scenario is medium low.

For the identification of the precipitation extremes the Simple Daily Intensity Index (SDII) was employed, defined as the quotient of precipitation amount of wet days and the number of wet days of a specified period, serving as measure of precipitation intensity on wet days, especially to examine tendencies of heavy precipitation events (Frich et al., 2002). The index was calculated for the present and future period, on a seasonal basis, defining a wet day as having precipitation of at least $1 \mathrm{~mm}$. However, emphasis will be given on the wet period and especially on winter, when the main part of precipitation in EM occurs (Xoplaki et al., 2000). Kostopoulou and Jones (2005) have demonstrated that the easternmost part of Mediterranean is characterised by decreasing trends of SDII for the period 1958-2000, however, statistically significant only in a few stations.

To investigate the relationship between SDII and $500 \mathrm{hPa}$ atmospheric circulation, the Regularized Canonical Correlation Analysis (RCCA) was employed, separately, for the present and future period. RCCA determines optimal pairs of concomitant spatial patterns that account for the maximum amount of variance within two data matrices $\mathbf{X}$, Y separately, and, at the same time, their optimally correlated time components. When the number of columns (data series of stations or grid points) exceeds the number of rows (data series length, usually covering few decades), the correlation matrices of $\mathbf{X}$ and $\mathbf{Y}$ tend to be ill-conditioned and their inverses unreliable. Therefore, a regularization step is included in the calculations by adding a regularization parameter $\lambda_{1}, \lambda_{2}$ on the diagonal of each correlation matrix of $\mathbf{X}$ and $\mathbf{Y}$, respectively (Leurgans et al., 1993). In the present study, the calculations were performed with the aid of the statistical language R (Gonzalez et al., 2008) and the method was applied to the gridded data of mean seasonal geopotential height values for a region extending from $60^{\circ} \mathrm{W}$ to $60^{\circ} \mathrm{E}$ and from $25^{\circ}$ to $70^{\circ} \mathrm{N}$ (data matrix $\mathbf{X}$ ) and to the seasonal SDII values (data matrix $\mathbf{Y}$ ) calculated from the corresponding HadRM3P grid points. In all cases, the first four canonical pairs are retained that have the highest correlations, trying to keep pairs with physical interpretability.

Then, the 90th percentile of SDII was calculated for each selected grid-point of the examined area on a seasonal basis in the present and future period. The extreme seasons were designated by the SDII exceedance of the 90th percentile in at least $25 \%$ of the grid-points in EM. The composite anomalies of $500 \mathrm{hPa}$ geopotential heights were then calculated from the long term averages at each grid point and the corresponding composite maps were constructed for the extreme seasons in the present and future climate.

The validation of HadAM3P $500 \mathrm{hPa}$ geopotential heights was performed against the corresponding NCEP/NCAR values - being used as "observed reference" - for the present period 1960-1990 over the greater European region (Anagnostopoulou et al., 2008) demonstrated that the biases between the two data sets are comparable to the natural variability of $500 \mathrm{hPa}$ geopotential height, while the two data sets exhibit similar variability over the whole examined area. The output of HadRM3P was verified against data of 40 stations data in EM for the same period, demonstrating an overestimation of precipitation extremes, with better representation in winter (Hanson et al., 2007; Hatzaki et al., 2009).

\section{RCCA results}

For the present winter period, the first RCC pair depicts an extended cyclonic (anticyclonic) anomalous circulation covering the whole European area that leads to an increase (decrease) of SDII over Greece, and mainly over Western Greece (Fig. 1a). On the contrary, decrease of SDII is found over the remaining examined area. The second pair displays the Eastern Atlantic pattern, which is characterized by three centres, a positive one over the British Isles, and two negative, over central Atlantic and Eastern Europe. In its negative phase, this pattern is associated with increasing precipitation intensity over Greece and Turkey, while a decrease is apparent over Cyprus and the easternmost part of the examined area (Fig. 1b). This is consistent with the belowaverage precipitation found across southern Europe during this phase (Climate Prediction Center-NOAA, 2008). The positive phase of the Scandinavia pattern appears in the third pair, which is associated with positive height anomalies, reflecting major blocking anticyclones over Scandinavia and western Russia (Fig. 1c). This pattern leads to increased SDII values over the examined area, consistent with the above average precipitation across central and southern Europe during this phase (Climate Prediction Center-NOAA, 2008). The fourth pair, in Fig. 1d, displays the Eastern Mediterranean Pattern (EMP) that forms between Northern Atlantic and EM at the upper levels mainly in winter (Hatzaki et al., 2007). When a cyclonic anomaly forms over Eastern Mediterranean, signifying the positive EMP phase, the precipitation intensity is above normal over the whole examined area. On the contrary, the negative phase is characterized by an intensification of the Atlantic anticyclone resulting in increased meridional flow of northerly component toward the central Mediterranean leading to a decrease of the precipitation intensity (Hatzaki et al., 2009).

With increasing concentrations of greenhouse gases, not only the climate regimes change, but also the large-scale circulation adjusts to achieve a new thermodynamical balance. The sea surface temperature (SST) gradients, as well as tropical convection can also have an impact on the upper-tropospheric circulation (Inatsu et al., 2002; Inatsu and Hoskins, 2004). Changes in any of these processes may have an impact on circulation in the future, and the fact that these are competing processes may explain the wide range 

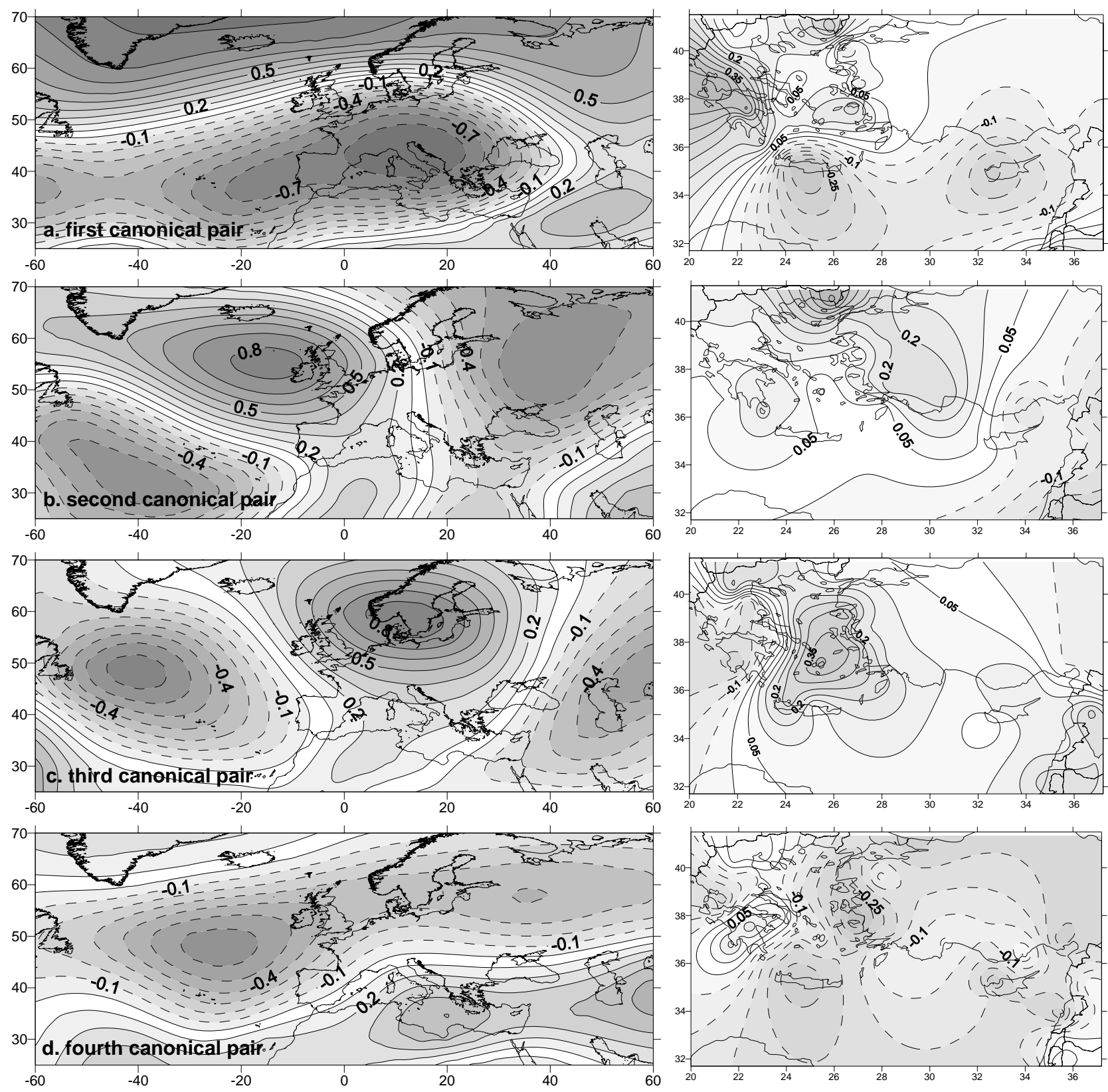

Fig. 1. Canonical correlation loadings of four RCCA pairs - (a), (b), (c) and (d), respectively - for the $500 \mathrm{hPa}$ geopotential heights (left column) and SDII (right column) for the present climate; dashed contours indicate negative values.

of results produced by different models that handle the delicate balance between these processes differently (Ulbrich and Christoph, 1999; Bengtsson et al., 2006). Moreover, it should be noted, though, that since uncertainties and limitations related to the future climatic scenarios have been stressed in international bibliography (e.g. Osborn, 2004; Bengsston et al., 2006; Stephenson et al., 2006; Solomon et al., 2007), as well as limitation related to the ability of the regional model to represent adequately the precipitation regime (Hanson et al., 2007), the results for the future climate should be considered with caution.
From the analysis for the future climate similar patterns are recognized with, however, relative translation and/or change in relative importance, following changes in large scale circulation and especially, in location and intensity of storm tracks. The first pair of the future resembles the third one of the present climate, displaying the negative phase of Scandinavia pattern that it is followed by decreased precipitation intensity mainly over Greece (Fig. 2a). It was found that the EMP continues to influence the regional climate of Eastern Mediterranean in the future, under warmer global conditions, similarly to the present climate as the second pair, 

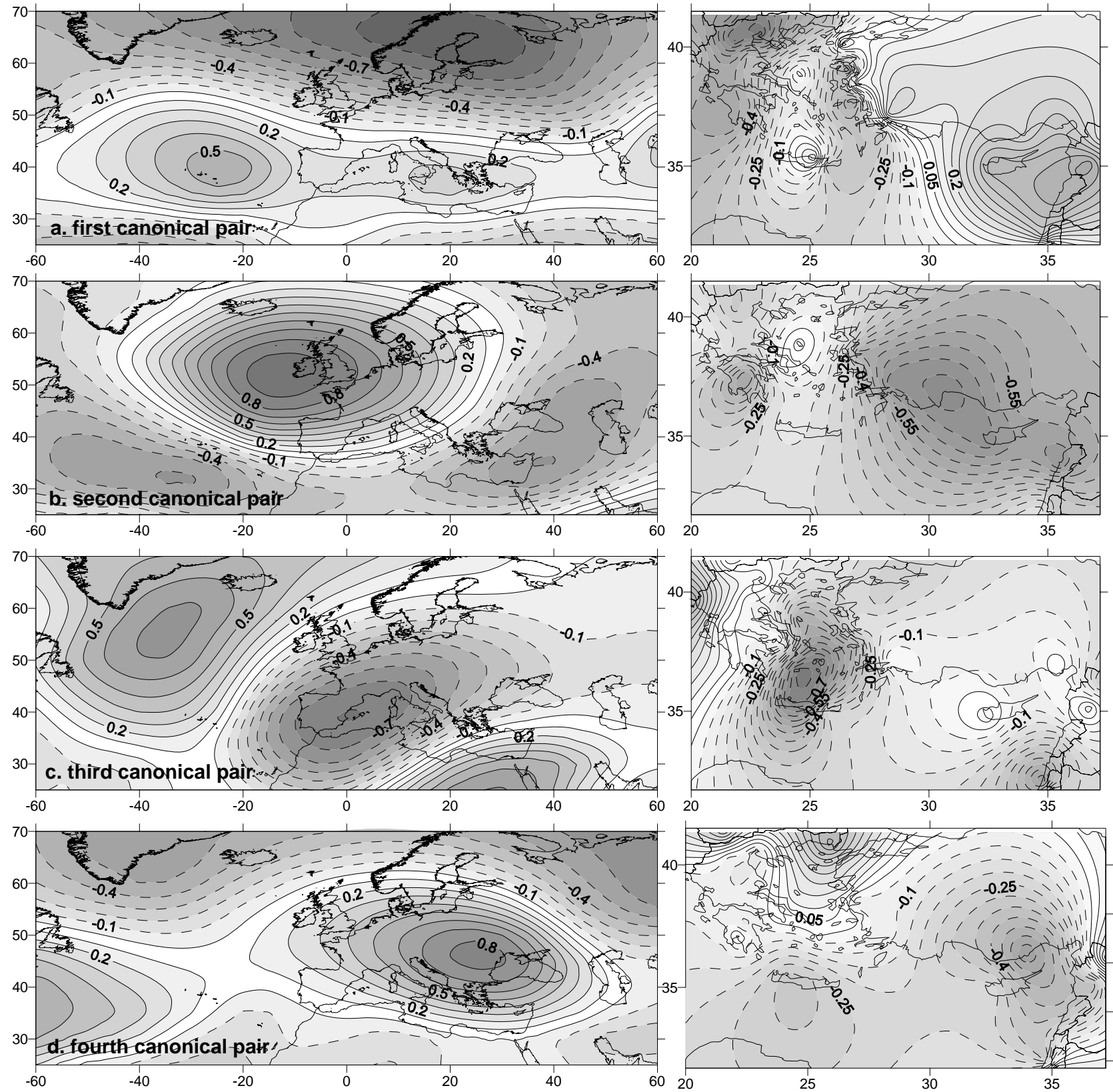

Fig. 2. Canonical correlation loadings of four RCCA pairs - (a), (b), (c) and (d), respectively - for the $500 \mathrm{hPa}$ geopotential heights (left column) and SDII (right column) for the future climate (B2a scenario); dashed contours indicate negative values.

but shifted eastwards, as found by Hatzaki et al. (2006). The sign of its impact in EM climate is the same compared to the control run, but with larger loadings suggesting a dominant role of the pattern during winter in the future (Fig. 2b). The third pair displays an extensive cyclonic circulation over southern Europe and an anticyclonic circulation over Africa leading to an increase in precipitation intensity to the western examined area followed by decrease in the eastern part (Fig. 2c). This pattern of circulation does not reflect a known low frequency pattern. Finally, the extended anticyclonic anomalous circulation (blocking) covering the whole European area in the fourth pair of the future RCCA exhibits an eastward shift of the pattern for the first pair of the present climate, which leads to decreasing precipitation intensity over the examined area (Fig. 2d). Oppositely, the cyclonic anomalous circulation over Europe results to increasing precipitation intensity over EM. It should be noted that the Eastern Atlantic pattern, depicted in the second pair for present climate analysis, is not present in the first four pairs of future analysis. 
The same study for the other two wet seasons revealed similar results. Specifically, during autumn a blocking system (Tyrlis and Hoskins, 2008) over European region predominates, both in present and future climate (as the first pair), leading to decreased daily precipitation intensity, especially in the future (not shown). The Scandinavian pattern and the EMP are displayed in the third and fourth pair, respectively, but with lower loading values, implying their weakened impact in the future autumn.

On the other hand, during spring the geopotential height loadings are more intense in the future in all examined canonical pairs, suggesting an increased impact of the prevailing large scale patterns on precipitation intensity. In particular, an extended anticyclonic system over the whole European region induces a wide decrease in precipitation intensity over Eastern Mediterranean. The Eastern Atlantic pattern, as well as the Scandinavian pattern, also affects the precipitation intensity both in present and future climate, in similar way as during winter (not shown).

\section{Composite analysis}

Following the methodology described in Sect. 2, five extreme winters with respect to the value of SDII were identified in the present period and six in the future period.

From Fig. 3a that displays the composite anomalies in the present climate, it can be seen that the dominant pattern related to extreme winters of intense precipitation in Eastern Mediterranean is the positive phase of EMP. In the future, the EMP continues to influence the extreme winters of Eastern Mediterranean, similarly to the present climate (Fig. 3b). It is characteristic that the extreme winters in the future climate were assigned to the positive phase of EMP with the aid of the standardised teleconnection index as defined in Hatzaki et al. (2006). Moreover, the corresponding anomalies are intensified as compared to the present. This is consistent with the results of Hatzaki et al. (2009) for the impact of EMP on precipitation intensity regime in Eastern Mediterranean in the present climate and the future climate under the $\mathrm{B} 2 \mathrm{a}$ scenario, demonstrating increase of the index during the positive phase over the whole examined area and mainly over the Aegean Sea.

\section{Conclusions}

The relationship of the low frequency circulation patterns of Northern Hemisphere with the precipitation intensity in EM in present and future climate is examined in this study. The study revealed that low frequency circulation patterns of Northern Hemisphere at the upper troposphere, such as the Eastern Atlantic and the Scandinavia patterns are related with the precipitation intensity in EM during the wet seasons, i.e. winter, spring and autumn. Furthermore, the EMP appears to be important atmospheric component that prevails
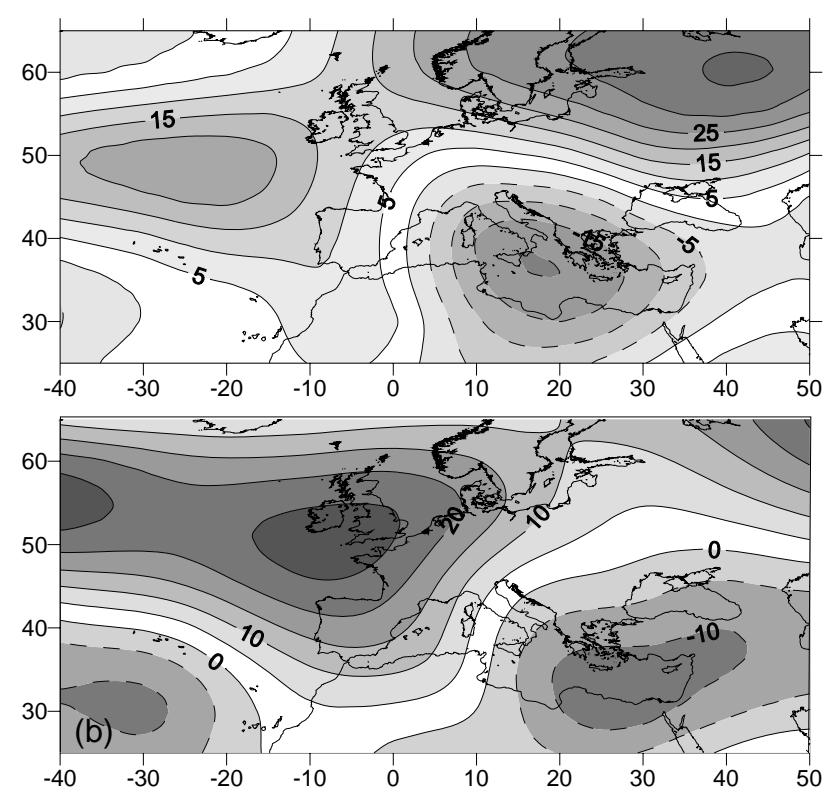

Fig. 3. Composite anomalies of $500 \mathrm{hPa}$ geopotential heights for the winters of extreme daily precipitation intensity (a) for the present climate (control run) and (b) for the future climate (B2a scenario); dashed contours indicate negative values; contour interval is $5 \mathrm{gpm}$.

during extreme precipitation winters in the present, as well as in the future climate. Overall, similar patterns are projected in the future, with, however, different magnitude, following the expected displacement and change of magnitude of the storm tracks.

The relevance of the study to the future projections of the large scale circulation and its impact to regional climate is important, because it reveals that well-known teleconnection patterns of Northern Hemisphere are still components of natural climatic variability, and, thus, they can contribute to explain the intra-annual variations of regional climate. Furthermore, better knowledge of the large scale circulation impact on regional climate provides a better basis for downscaling of the global climatic model simulations over the EM region (Haylock et al., 2006; Tolika et al., 2007).

Acknowledgements. The present study was funded through the Project "PENED 2003" with 75\% from European Union-European Social Fund (E. S. F.) and 25\% from National Funds-Ministry of Development-General Secretariat of Research and Technology and from private funds.

Edited by: S. Michaelides, K. Nicolaides, and A. Orphanou Reviewed by: two anonymous referees 


\section{References}

Anagnostopoulou, C., Tolika, K., Maheras, P., Kutiel, H., and Flocas, H. A.: Performance of the general circulation model HadAM3P in simulating circulation types over the Mediterranean region, Int. J. Climatol., 28, 185-203, 2008.

Bengtsson, L., Hodges, K. I., and Roecher, E.: Storm tracks and climate change, J. Climate, 19, 3518-3543, 2006.

Climate Prediction Center-NOAA: http://www.cpc.noaa.gov/data/ teledoc/telecontents.shtml, last access: 8 September 2009, 2008.

Fowler, H. J. and Kilsby, C. G.: Implications of changes in seasonal and annual extreme rainfall, Geophys. Res. Lett., 30, 1720, doi:10.1029/2003GL017327, 2003.

Frich, P., Alexander, L. V., Della-Marta, P., Gleason, B., Haylock, M., Klein Tank, A. M. G., and Peterson, T.: Observed coherent changes in climatic extremes during the second half of the twentieth century, Clim. Res., 19, 193-212, 2002.

Gonzalez, I., Dejean, S., Martin, P. G. P., and Baccini, A.: CCA: An $\mathrm{R}$ package to extend canonical correlation analysis, available online at: http://www.jstatsoft.org/v23/i12, last access: 8 September 2009, J. Stat. Softw., 23(12), 2008.

Hanson, C., Palutikof, J. P., Livermore, M. T. J., et al.: Modelling the impact of climatic extremes: An overview of MICE project, Climatic Change, 81, 163-177, 2007.

Hatzaki, M., Flocas, H. A., Asimakopoulos, D., Giannakopoulos, C., and Maheras, P.: Study of future climatic variations of a teleconnection pattern affecting Eastern Mediterranean, Global Nest J., 8(3), 195-203, 2006.

Hatzaki, M., Flocas, H. A., Asimakopoulos, D., and Maheras, P.: The Eastern Mediterranean teleconnection pattern: Identification and definition, Int. J. Climatol., 27, 727-737, 2007.

Hatzaki, M., Flocas, H. A., Giannakopoulos, C., and Maheras, P.: The impact of the eastern Mediterranean teleconnection Pattern on the Mediterranean climate, J. Climate, 22, 977-992, 2009.

Haylock, M. R. and Goodess, C. M.: Interannual variability of European extreme winter rainfall and links with mean large-scale circulation, Int. J. Climatol., 24, 759-776, 2004.

Houssos, E., Lolis, C. J., and Bartzokas, A.: Atmospheric circulation patterns associated with extreme precipitation amounts in Greece, Adv. Geosci., 17, 5-11, 2008, http://www.adv-geosci.net/17/5/2008/.

Inatsu, M. and Hoskins, B. J.: The Zonal Asymmetry of the Southern Hemisphere Winter Storm Track, J. Climate, 17, 4882-4892, 2004.

Inatsu, M., Mukougawa, H., and Xie, S.: Tropical and extratropical SST effects on the midlatitude storm track, J. Meteor. Soc. Jpn., 80, 1069-1076, 2002.

Kostopoulou, E. and Jones, P. D.: Assessment of climate extremes in the Eastern Mediterranean, Meteorol. Atmos. Phys., 89, 69$85,2005$.
Kutiel, H., Maheras, P., Türkes, M., and Paz, S.: North Sea-Caspian Pattern - an upper level atmospheric teleconnection affecting the eastern Mediterranean - Implications on the regional climate, Theor. Appl. Climatol., 72, 173-192, 2002.

Leurgans, S. E., Moyeed, R. A., and Silverman, B. W.: Canonical correlation analysis when the data are curves, J. Roy. Stat. Soc., 55B, 725-740, 1993.

Littmann, T.: An empirical classification of weather types in the Mediterranean Basin and their interrelation with rainfall, Theor. Appl. Climatol., 66, 161-171, 2000.

Maheras, P., Xoplaki, E., and Kutiel, H.: Wet and dry monthly anomalies across the Mediterranean basin and their relationship with circulation 1860-1990, Theor. Appl. Climatol., 64, 189199, 1999.

Osborn, T. J.: Simulating the winter North Atlantic Oscillation: The roles of internal variability and greenhouse gas forcing, Clim. Dynam., 22, 605-623, 2004.

Santos, J. A., Corte-Real, J., Ulbrich, U., and Palutikof, J.: European winter precipitation extremes and large-scale circulation: a coupled model and its scenarios, Theor. Appl. Climatol., 87, 85102, 2007.

Solomon, S., Qin, D., Manning, M., Chen, Z., Marquis, M., Averyt, K. B., Tignor, M., and Miller, H. L.: Climate Change 2007: The Physical Science Basis, Cambridge University Press, 2007.

Stephenson, D. B., Pavan, V., Collins, M., Junge, M., and Quadrelli, R.: North Atlantic Oscillation response to transient greenhouse gas forcing and the impact on European winter climate: A CMIP2 multi-model assessment, Clim. Dynam., 27, 401-420, 2006.

Tartaglione, N., Maugeri, M., Dalan, F., Brunetti, M., Nanni, T., and Speranza, A.: Searching for resemblance between large-scale sea level pressure patterns leading to "intense" precipitation events over Italy, Theor. Appl. Climatol., 95, 183-196, 2009.

Tolika, K., Maheras, P., Vafiadis, M., Flocas, H. A., and ArseniPapadimitriou, A.: Simulation of seasonal precipitation and raindays over Greece: A statistical downscaling technique based on artificial neural networks (ANNs), Int. J. Climatol., 27, 861-881, 2007.

Tyrlis, E. and Hoskins, B. J.: Aspects of a Northern Hemisphere Atmospheric Blocking Climatology, J. Atmos. Sci., 65, 1638$1651,2008$.

Ulbrich, U. and Christoph, M.: A shift of the NAO and increasing storm track activity over Europe due to anthropogenic greenhouse gas forcing, Clim. Dynam., 15, 551-559, 1999.

Wibig, J.: Precipitation in Europe in relation to circulation patterns at the $500 \mathrm{hPa}$ level, Int. J. Climatol., 19, 253-269, 1999.

Xoplaki, E., Luterbacher, J., Burkard, R., Patrikas, I., and Maheras, P.: Connection between the large-scale $500 \mathrm{hPa}$ geopotential height fields and precipitation over Greece during wintertime, Clim. Res., 14(2), 129-146, 2000. 